\title{
Prevalence of respiratory symptoms, bronchial hyperresponsiveness and atopy among adults: West and East Germany
}

\author{
D. Nowak*, J. Heinrich**, R. Jörres*, G. Wassmer**, J. Berger+, E. Beck**, \\ S. Boczor + , M. Claussen + , H.E. Wichmann**†, H. Magnussen*
}

Prevalence of respiratory symptoms, bronchial hyperresponsiveness and atopy among adults: West and East Germany. D. Nowak, J. Heinrich, R. Jörres, G. Wassmer, J. Berger, E. Beck, S. Boczor, M. Claussen, H.E. Wichmann, H. Magnussen. @eERS Journals Ltd 1996.

ABSTRACT: The prevalence of respiratory symptoms, atopic sensitization and bronchial hyperresponsiveness was compared in a random sample of adults, 20-44 yrs of age, in two cities in West and East Germany, Hamburg and Erfurt, respectively. There were much higher levels of outdoor air pollution due to sulphur dioxide and suspended particulates in Erfurt, and major differences in living conditions during the last $\mathbf{4 0}$ yrs.

Within the European Respiratory Health Survey, a short questionnaire was answered by $3,156(80 \%$ response rate) subjects in Hamburg and $3,272(74 \%)$ in Erfurt. A subset of responders to the short questionnaire completed a long questionnaire, spirometry, methacholine or bronchodilator test, skin test, and total and specific immunoglobulin $E$ (IgE) measurements, with a total number of 1,159 participants in Hamburg and 731 in Erfurt.

Six out of 8 questions on respiratory symptoms and diagnoses were answered in the affirmative more frequently in Hamburg than in Erfurt. In Hamburg, mean forced expiratory volume in one second (FEV1) \% of predicted was 105 vs $107 \%$ in Erfurt $(p<0.0001)$, and bronchial hyperresponsiveness was more frequently observed in Hamburg than in Erfurt $(25$ vs $19 \%$; $\mathbf{p}<0.05)$. Atopic sensitization was more prevalent in Hamburg than in Erfurt regarding the results of skin tests against grass pollen $(24$ vs $19 \%$; $\mathbf{p}<0.05)$, birch pollen $(19$ vs $8 \%$; $<<0.0005)$, cat (10 vs 2\%; $\mathbf{p}<0.0005$ ), and Dermatophagoides pteronyssinus (14 vs 10\%; $\mathbf{p}<0.05$ ). This was reflected by the prevalences of positive specific IgE values, which were higher in Hamburg than in Erfurt for grass (26 vs 20\%; p<0.05), birch (20 vs $10 \%$; p<0.0005) and cat (12 vs 8\%; p<0.05). In Hamburg, compared to Erfurt, there was: a lower mean number of siblings $(\mathbf{p}<0.005)$; a higher degree of childhood and current exposure to environmental tobacco smoke $(p<0.005)$; and a higher frequency of fitted carpets and reported mould or mildew inside the house $(\mathbf{p}<0.005)$.

Therefore, these data may support the hypothesis that childhood factors and exposure to indoor allergens and irritants may have been more relevant for the development of asthma and atopy than the potential long-term exposure to high concentrations of sulphur dioxide and particulate matter.

Eur Respir J., 1996, 9, 2541-2552.

\begin{abstract}
*Krankenhaus Grosshansdorf, Zentrum für Pneumologie und Thoraxchirurgie, Grosshansdorf, Germany. **GSF-Forschungszentrum für Umwelt und Gesundheit, Institut für Epidemiologie, Neuherberg, Germany. +Universitätskrankenhaus Eppendorf, Institut für Mathematik und Datenverarbeitung in der Medizin, Hamburg, Germany. "Bergische Universität Gesamthochschule Wuppertal, Fachgebiet Arbeitssicherheit und Umweltmedizin, Wuppertal, Germany.
\end{abstract}

Correspondence: H. Magnussen

Krankenhaus Grosshansdorf

Zentrum für Pneumologie und Thoraxchirurgie

Wöhrendamm 80

D-22927 Grosshansdorf

Germany

Keywords: Asthma

atopy

EC respiratory health survey

epidemiology

hyperresponsiveness

indoor factors

Received: August 181995

Accepted after revision August 251996

It is the policy of the EC Respiratory Health Survey to indicate that the results presented are from a local analysis, and any final international comparison may use a different form of analysis.

Supported by a grant from the Bundesminster für Forschung und Technologie.
West and East Germany have experienced different living conditions over the last 40 yrs. The most striking difference was the markedly higher level of ambient air pollution in East Germany as compared to West Germany, mainly due to sulphur dioxide and particulates. In addition, there were differences indoors reflected, e.g. by housing, heating and ventilation, and several further factors that influence exposure to pollutants and allergens. On the other hand, these two populations were ethnically identical. The German reunification in 1990 offered the unique opportunity to compare the influence of external factors on respiratory health in two cities in West and East Germany, Hamburg and Erfurt, respectively. Thus, our research examined whether there were differences in the prevalence of atopic sensitization and respiratory diseases in West and East Germany, and to what extent they might be explained by a variety of risk factors with different distributions in the two cities.

Therefore, in both cities, we studied respiratory symptoms, spirometry, airway responsiveness, skin reactivity, and total and specific immunoglobulin $\mathrm{E}(\operatorname{IgE})$, as well as a panel of potential risk factors for respiratory diseases, in random samples of adults from the general 
population. For this purpose, we followed the protocol of the European Community (EC) Respiratory Health Survey [1].

\section{Material and methods}

\section{Study areas}

Hamburg is a mainly commercial and administrative centre, located in the flat north of former West Germany about $150 \mathrm{~km}$ from the North Sea and $50 \mathrm{~km}$ from the Baltic Sea. The total population of Hamburg is approximately 1.67 million. There is a low level of combustion-related air pollution, in contrast to a large amount of traffic. Most of the year, there are predominantly Western coastal winds. Erfurt is an industrial and commercial city, located in a shallow basin in the south-west of the former German Democratic Republic, with a total population of about 210,000 inhabitants. Over the last few decades, only a small amount of traffic was present, but a high level of air pollution due to combustive sources, such as burning of coal with a high content of sulphur in the majority of private households and municipal power plants. In Erfurt, there is normally little wind. Otherwise, climatic conditions are similar between study centres. Within the period from 1985 to 1989 , annual mean concentrations of sulphur dioxide and suspended particulates were 31 and $53 \mu \mathrm{g} \cdot \mathrm{m}^{-3}$, respectively, in Hamburg as compared to 264 and $137 \mu \mathrm{g} \cdot \mathrm{m}^{-3}$ (for suspended particulates in 1988-1989), respectively, in Erfurt. The annual mean concentration of nitrogen dioxide $\left(\mathrm{NO}_{2}\right)$ was $38 \mu \mathrm{g} \cdot \mathrm{m}^{-3}$ in Hamburg; no data are available for Erfurt.

\section{Subjects}

Random samples of 4,500 (Hamburg) and 4,990 (Erfurt) subjects born between 1945 and 1971 were drawn from the lists of the Offices of Population Censuses. Thus, the target population comprised, respectively, 0.6 and $5.8 \%$ of the total population aged 20-44 yrs. Only subjects of this age range were included in the data evaluation at each stage, according to the actual age at the time of answer to the questionnaire or measurement. In Hamburg and Erfurt, 3.5 and $0.7 \%$ of the subjects under study had been born outside Germany. The study was performed from 1990 to 1992.

\section{Study design}

This was a cross-sectional study using a two-step approach. In Stage I, the screening questionnaire standardized within the EC Respiratory Health Survey was mailed. Those subjects who did not respond within a period of 2-4 months received up to two letters to remind them. In Hamburg, all subjects not responding to the mailed questionnaire were contacted by up to five phone calls by trained interviewers at different times, including evenings and weekends. Additionally, in a random $20 \%$ sample of subjects not responding to letters and phone calls, up to three attempts at a home visit were made. In Erfurt, due to lower availability of telephones, all subjects not responding to the mailed questionnaire had to be contacted by home visits, which were made up to three times.

Stage II comprised a detailed questionnaire, spirometric measurements, methacholine or bronchodilator inhalation tests, skin-testing, and determination of total and specific IgE. In Hamburg, all subjects who responded to the Stage I screening questionnaire were invited by phone, letter or home visit to attend subsequent Stage II tests, and in Erfurt, a random sample of the Stage I responders $(41 \%)$ was invited by letter or home visit to the Stage II tests. The identical methodology of the Stage II tests was followed in the two centres.

The study protocol had been approved by the Local Ethics Committees, and written informed consent was obtained from all participants.

\section{Long questionnaire}

The long questionnaire, with 71 items, had been developed from pre-existing questionnaires: questions relating to respiratory symptoms and medical history were taken from the International Union Against Tuberculosis and Lung Disease (IUATLD) questionnaire [2-4]; those on smoking from the American Thoracic Society (ATS) questionnaire [5]; and those on occupation and social status from the Office of Population Censuses and Surveys [6]. Questions on housing conditions were based on those used in the Children's Health Study performed at the Harvard School of Public Health. The questionnaire had been translated from the English version into German and, after piloting in 30 volunteers and checking for comprehensibility, back-translated into English.

\section{Spirometry}

Spirometric measurements were performed using pneumotachograph-based electronic spirometers (Compact Pneumo Lab, and PSC-PC, Jaeger, Würzburg, Germany) that met published standards [7]. In smokers and subjects using inhaled medication, lung function testing was carried out at least $1 \mathrm{~h}$ after the last cigarette had been smoked or $4 \mathrm{~h}$ after the use of any inhaler. Subjects carried out five forced vital capacity (FVC) manoeuvres, and the forced expiratory volume in one second (FEV1) and FVC of the best two technically satisfactory manoeuvres were recorded. Manoeuvres were accepted as technically satisfactory: if the variation of the two best FEV1 values was below 5\%; if the back-extrapolated volume was lower than $100 \mathrm{~mL}$ or $5 \% \mathrm{FVC}$; and if the expiratory time was at least $6 \mathrm{~s}$. If the subjects failed to produce two technically satisfactory manoeuvres after 5 attempts, another four more attempts were allowed.

\section{Methacholine challenge or bronchodilator testing}

Methacholine challenges were performed in all subjects who were willing to participate, able to perform 
successful FEV1 and FVC manoeuvres (showing an FEV1 above $70 \%$ of the mean predicted, not lower than $1.5 \mathrm{~L})$. Subjects who currently were on antiasthma treatment were given an appointment for challenge when they had taken their inhalers at least $4 \mathrm{~h}$ beforehand and their oral medication at least $8 \mathrm{~h}$ beforehand. Challenges were performed using the Mefar MB3 dosimeter and five individually calibrated dosimeters (Mefar srl Bovezzo, Italy). After measuring baseline values and the airway response to the diluent, increasing concentrations of standard methacholine (Provocholine; Hoffmann La Roche, Basel, Switzerland) were given. According to a history of respiratory symptoms, a short protocol with fourfold increases and a long protocol with twofold increases in methacholine concentrations was used. In either protocol, the subjects took a defined number of breaths (1-4), at intervals of $6 \mathrm{~s}$, starting from functional residual capacity (FRC), slowly inhaling to total lung capacity (TLC), and holding their breath for $3 \mathrm{~s}$. The FEV1 manoeuvre was performed 2 min after each dose. Provocation was stopped when FEV1 had dropped by $20 \%$ as compared to postdiluent values or after a maximum cumulative dose of methacholine of $2.0 \mathrm{mg}$. In this way the cumulative dose of methacholine necessary to decrease FEV1 by $20 \%$ (PD20) was determined. In addition, according to CHINN et al. [8], the dose-response slope $(\gamma)$ was calculated by fitting the line "fall in FEV $1=\delta+\gamma \times$ dose" using the least-squares method. The dose-response slope was considered as an index of responsiveness.

Any subject with a baseline FEV1 below $70 \%$ of the mean predicted value received $200 \mu \mathrm{g}$ of salbutamol by metered-dose inhaler and volumatic in a standardized fashion. Spirometry was performed $10 \mathrm{~min}$ after the administration of the bronchodilator. A more than $15 \%$ increase in FEV1 was considered to be a positive response.

\section{Skin-testing}

The sensitivity to five common aeroallergens was assessed by skin-testing on the forearms with standardized allergen extracts. The allergens applied were grass, birch, cat, Dermatophagoides pteronyssinus, Cladosporium herbarum, and Alternaria alternata. All allergens, except grass, were supplied on Phazets for the purposes of the EC Respiratory Health Survey by Pharmacia, Uppsala, Sweden [9]. The grass allergen could not be tested by Phazets that were not allowed to be used in Germany, which was also true for some other allergens. Therefore, a batch from Allergopharma, Reinbek, Germany, was used. For the Phazet testing, the respective positive (histamine $10 \mathrm{mg} \cdot \mathrm{mL}^{-1}$ ) and negative controls (uncoated Phazet) were used. Results were read after 15 min by drawing around the perimeter of the wheal with a ballpoint pen. Using a strip of transparent tape, the prints were transferred to the data sheet. Wheal diameters were read at the widest point and at $90^{\circ}$ to the diameter at the midpoint. A skin test was considered positive if a mean wheal diameter of at least $3 \mathrm{~mm}$ to at least one allergen was present, and if the wheal diameter to histamine was $\geq 3 \mathrm{~mm}$, and to uncoated Phazets $<3 \mathrm{~mm}$.

\section{Serum $\operatorname{Ig} E$}

Sera were stored at $-20^{\circ} \mathrm{C}$ until analysed. Total and specific serum IgE against grass, birch, cat, D. pteronyssinus, and $C$. herbarum were measured centrally by Pharmacia (Uppsala, Sweden) using the Pharmacia CAP system.

\section{Quality control}

All fieldworkers attended a central training seminar prior to the study. Within- and between-fieldworker variability had to be below $5 \%$ for FVC and FEV1, and below $30 \%$ for mean weal diameters of histamine Phazets. Nebulizer output was checked gravimetrically every month to ensure a comparable and constant output. High performance liquid chromatography analyses of the methacholine solutions were performed in a central laboratory twice during the study. The co-ordinator of the EC Respiratory Health Survey visited the centres and checked that the protocol was followed adequately without deviation.

\section{Statistical analysis}

Crude prevalences are given for both populations. In addition, for the subjects tested in Erfurt, prevalence figures have been directly adjusted according to the age and gender distribution in the subjects tested in Hamburg. All statistical comparisons were performed using these adjusted prevalences. Comparisons were made using Student's t-test for continuous variables, and Chi-squared tests to compare prevalences between study populations. In the descriptive tables, only point prevalence estimates are given without confidence intervals, as they were relatively small in this large size study. Multiple logistic regression analysis was performed to estimate the odds ratios of reactor status (positive skin test, positive specific serum IgE, and bronchial hyperresponsiveness) in relation to the two populations, gender, and potential risk factors. The Statistical Analysis System (SAS) and the Statistical Package for Social Sciences (SPSS) software were used for the calculations.

\section{Results}

\section{Participation}

With respect to the number of eligible subjects, overall response rates to the Stage I screening questionnaire were $80 \%$ in Hamburg and 74\% in Erfurt. Defining a Stage II participant as a subject who had completed at least the long questionnaire, the overall participation rates as related to the target population were $37 \%$ in Hamburg and 55\% in Erfurt (table 1). The distribution of gender and age did not significantly differ between responders to Stage II and the target populations in Hamburg and Erfurt. 
Table 1. - Data base in Hamburg and Erfurt

\begin{tabular}{|c|c|c|c|c|c|c|}
\hline & \multicolumn{3}{|c|}{ Hamburg } & \multicolumn{3}{|c|}{ Erfurt } \\
\hline & M & $\mathrm{F}$ & $\Sigma$ & M & $\mathrm{F}$ & $\Sigma$ \\
\hline $\begin{array}{l}\text { Local population } 20-44 \text { yrs of age } \\
\text { (December } 31,1990 \text { ) }\end{array}$ & 312230 & 304826 & 617056 & 37711 & 39026 & 76737 \\
\hline \multicolumn{7}{|l|}{ Stage I } \\
\hline Target population & 1907 & 2027 & $3934(0.6)$ & 2126 & 2303 & $4429(6)$ \\
\hline Responders & 1512 & 1644 & $3156(80)$ & 1523 & 1749 & $3272(74)$ \\
\hline \multicolumn{7}{|l|}{ Stage II } \\
\hline Target population & 1512 & 1644 & $3156(100)$ & 653 & 685 & $1338(41)$ \\
\hline Responders (long questionnaire) & 588 & 571 & $1159(37)$ & 376 & 355 & $731(55)$ \\
\hline Spirometry & 516 & 455 & 971 & 341 & 312 & 653 \\
\hline Methacholine challenge & 497 & 437 & 934 & 314 & 279 & 593 \\
\hline Bronchodilator challenge & 1 & 5 & 6 & 0 & 3 & 3 \\
\hline Skin test & 517 & 455 & 972 & 375 & 355 & 730 \\
\hline Serum IgE & 403 & 336 & 739 & 373 & 345 & 718 \\
\hline
\end{tabular}

\section{Screening questionnaire}

According to the screening questionnaire symptom prevalence in Hamburg was higher than in Erfurt for wheezing, being woken up by an attack of coughing, having had an attack of asthma within the previous 12 months, taking asthma medicine, or having nasal allergies including hay fever $(\mathrm{p}<0.0005$ each). At least one out of a combination of questions suggestive of asthma (i.e. questions 1.2, 5 and 6) was answered in the affirmative in $14 \%$ of the subjects in Hamburg and $8 \%$ of those in Erfurt.

\section{Long questionnaire}

The most relevant answers from the long questionnaire are given in table 2 (regarding symptom prevalence) table 3 (regarding potential risk factors), and table 4 (symptoms related to exposure).

Respiratory symptoms. The screening questions were also repeated in the long questionnaire. We compared the prevalence of positive answers to these questions between participants in stage I and participants in Stage II. No significant differences were present either in Hamburg or in Erfurt.

Table 2. - Respiratory symptoms according to long questionnaire in Hamburg and Erfurt

\begin{tabular}{|c|c|c|c|c|c|c|c|c|c|}
\hline & & \multicolumn{3}{|c|}{ Hamburg } & \multicolumn{4}{|c|}{ Erfurt } & \multirow[b]{2}{*}{$\mathrm{p}$-value } \\
\hline & & M & $\mathrm{F}$ & $\Sigma$ & M & $\mathrm{F}$ & $\Sigma$ & Adjusted ${ }^{\#}$ & \\
\hline 1. & $\begin{array}{l}\text { Have you had wheezing or whistling in your } \\
\text { chest at any time in the last } 12 \text { months? }\end{array}$ & 20.4 & 20.7 & 20.6 & 8.0 & 11.3 & 9.6 & 9.4 & $<0.0001$ \\
\hline 1.1. & $\begin{array}{l}\text { Have you been at all breathless when the } \\
\text { wheezing noise was present? }\end{array}$ & 6.5 & 11.0 & 8.7 & 4.3 & 3.9 & 4.1 & 3.9 & 0.0001 \\
\hline 1.2. & $\begin{array}{l}\text { Have you had this wheezing or whistling } \\
\text { when you did not have a cold? }\end{array}$ & 12.8 & 13.3 & 13.0 & 5.6 & 5.1 & 5.3 & 5.1 & $<0.0001$ \\
\hline 2. & $\begin{array}{l}\text { Have you woken up with a feeling of } \\
\text { tightness in your chest at any time in } \\
\text { the last } 12 \text { months? }\end{array}$ & 8.0 & 12.8 & 10.4 & 6.5 & 6.8 & 6.7 & 6.8 & 0.0097 \\
\hline 3. & $\begin{array}{l}\text { Have you been woken by an attack of } \\
\text { shortness of breath at any time in the } \\
\text { last } 12 \text { months? }\end{array}$ & 3.7 & 5.4 & 4.6 & 2.7 & 3.7 & 3.1 & 3.3 & 0.1767 \\
\hline 4. & $\begin{array}{l}\text { Have you been woken by an attack of } \\
\text { coughing at any time in the last } 12 \text { months? }\end{array}$ & 21.5 & 32.6 & 26.9 & 9.8 & 14.1 & 11.9 & 12.0 & $<0.0001$ \\
\hline 5. & $\begin{array}{l}\text { Have you had an attack of asthma in the } \\
\text { last } 12 \text { months? }\end{array}$ & 1.2 & 3.7 & 2.4 & 0.5 & 0.8 & 0.7 & 0.6 & 0.0038 \\
\hline 6. & $\begin{array}{l}\text { Are you currently taking any medicine } \\
\text { (including inhalers, aerosols or tablets) } \\
\text { for asthma? }\end{array}$ & 0.7 & 3.2 & 1.9 & 0.3 & 0.6 & 0.4 & 0.4 & 0.0048 \\
\hline 7. & $\begin{array}{l}\text { Do you usually bring up any phlegm from } \\
\text { your chest first thing in the morning during } \\
\text { winter? }\end{array}$ & 10.6 & 8.9 & 9.8 & 12.0 & 5.9 & 9.1 & 9.0 & 0.5870 \\
\hline \multirow[t]{2}{*}{8.} & $\begin{array}{l}\text { Do you have nasal allergies including } \\
\text { hay fever? }\end{array}$ & 24.4 & 24.3 & 24.4 & 11.4 & 13.0 & 12.2 & 12.2 & $<0.0001$ \\
\hline & $\begin{array}{l}\text { At least one symptom out of questions } \\
1.2,5 \text { or } 6\end{array}$ & 13.6 & 14.4 & 14.0 & 5.6 & 5.4 & 5.5 & 5.3 & $<0.0001$ \\
\hline
\end{tabular}

Values are percentage positive answers. \#: adjusted for age and gender distribution in Hamburg. M: male; F: female. 
Table 3. - Distribution of potential risk factors for respiratory disease and atopy in Hamburg and Erfurt, according to long questionnaire

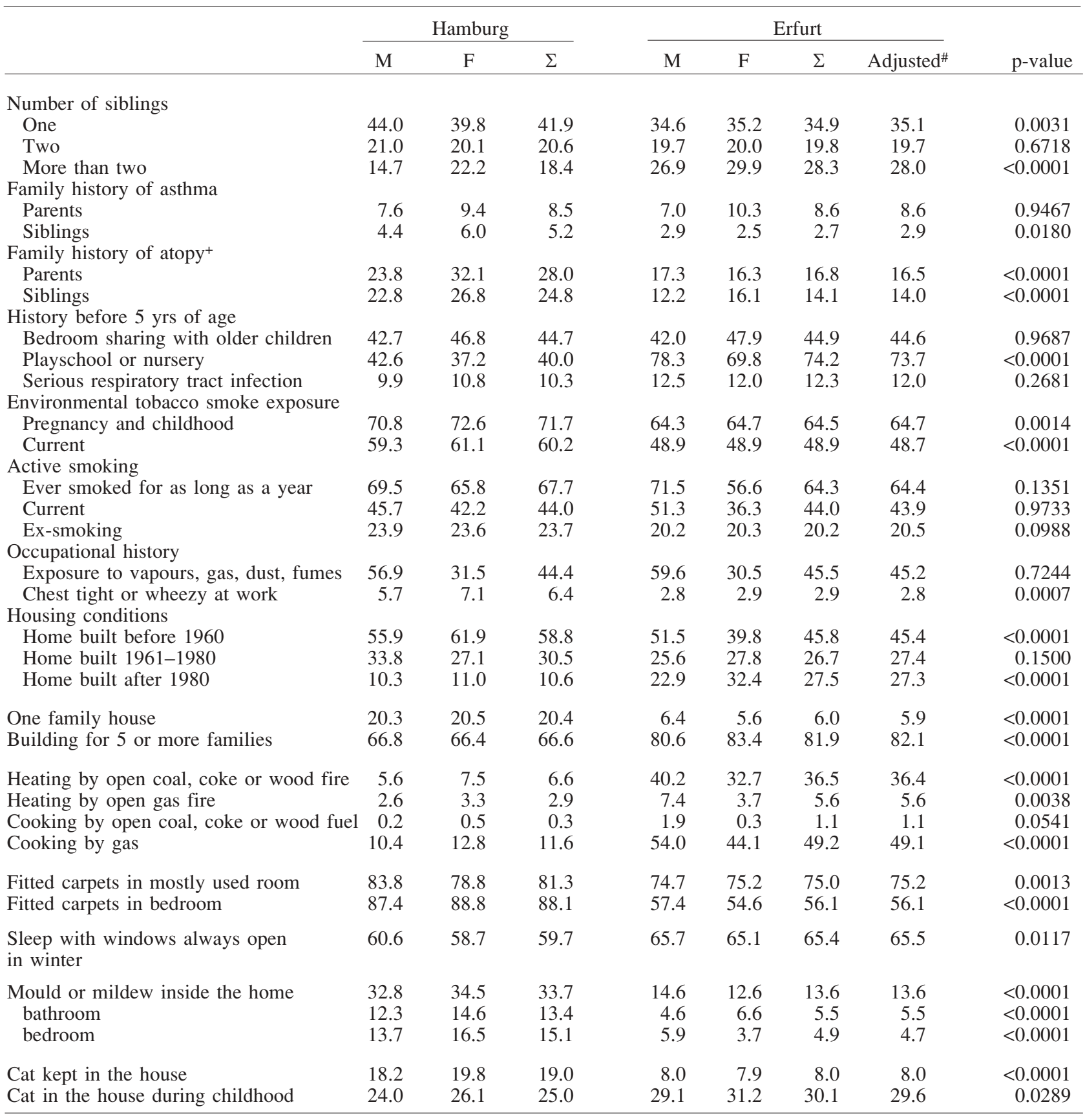

Values are percentages. \#: adjusted for age and gender distribution in Hamburg; +: eczema, skin or nasal allergy or "hay fever"; M: male; F: female.

Family and childhood history. The average number of siblings was higher among the participants from Erfurt than in those from Hamburg $(\mathrm{p}<0.005)$. Whereas more subjects in Hamburg reported asthma among siblings $(\mathrm{p}<0.05)$, no such difference was reported for their parents' generation. A family history of atopy, however, was more frequently reported among both siblings and parents in Hamburg than in Erfurt $(\mathrm{p}<0.0005$ each). Many more subjects in Erfurt had gone to a playschool or nursery before the age of 5 yrs $(\mathrm{p}<0.0005)$, but a similar prevalence was reported for serious childhood respiratory tract infections in both cities.
Active and passive smoking. Although the percentage of current and ex-smokers was similar in either city, more subjects reported childhood and current exposure to environmental tobacco smoke in Hamburg $(\mathrm{p}<0.005$ each).

Occupational history. An occupational exposure to vapours, gas, dust and fumes was reported with similar frequencies in both cities, but more subjects complained of work-related respiratory symptoms in Hamburg than in Erfurt $(\mathrm{p}<0.005)$. 
Table 4. - Symptoms related to exposure in Hamburg and Erfurt

\begin{tabular}{|c|c|c|c|c|c|c|c|c|}
\hline & \multicolumn{3}{|c|}{ Hamburg } & \multicolumn{4}{|c|}{ Erfurt } & \multirow[b]{2}{*}{ p-value } \\
\hline & M & $\mathrm{F}$ & $\Sigma$ & M & $\mathrm{F}$ & $\Sigma$ & Adjusted $\#$ & \\
\hline \multicolumn{9}{|l|}{ Exposure to animals or dust } \\
\hline Cough, wheeze, tightness, shortness of breath & 14.1 & 20.5 & 17.3 & 5.6 & 7.3 & 6.4 & 6.1 & $<0.0001$ \\
\hline Nose or eye symptoms & 29.0 & 36.8 & 32.8 & 18.1 & 20.6 & 19.3 & 19.0 & $<0.0001$ \\
\hline \multicolumn{9}{|l|}{ Exposure to trees, grass or flowers } \\
\hline Cough, wheeze, tightness, shortness of breath & 9.0 & 11.2 & 10.1 & 1.3 & 2.8 & 2.1 & 2.1 & $<0.0001$ \\
\hline Nose or eye symptoms & 28.1 & 30.8 & 29.4 & 10.1 & 16.1 & 13.0 & 12.8 & $<0.0001$ \\
\hline \multicolumn{9}{|l|}{ Symptoms after food intake } \\
\hline Breathlessness & 1.2 & 2.6 & 1.9 & 0.3 & 0.3 & 0.3 & 0.3 & 0.0020 \\
\hline Rash or itchy skin & 7.3 & 10.5 & 8.9 & 2.2 & 2.0 & 2.1 & 2.1 & $<0.0001$ \\
\hline \multicolumn{9}{|l|}{ Work-related symptoms } \\
\hline Tightness or wheeze & 1.2 & 2.1 & 1.7 & 1.4 & 0.3 & 0.9 & 0.8 & 0.1428 \\
\hline
\end{tabular}

Values are percentages. \#: adjusted for age and gender distribution in Hamburg. M: male; F: female.

Housing conditions. In Hamburg, there was a higher percentage of subjects living in older houses and in smaller housing units $(\mathrm{p}<0.005$ each). Many more subjects in Erfurt reported heating by open coal, coke, or wood fire, and heating or cooking by gas $(\mathrm{p}<0.005$ each). In Hamburg, more people had fitted carpets, and more reported mould or mildew inside the house $(\mathrm{p}<0.005$ each). Whereas slightly more subjects from Erfurt had lived with a cat in the house during childhood $(p<0.05)$, many more people in Hamburg were currently keeping cats in the house $(\mathrm{p}<0.0005)$.

Symptoms related to specific exposure. As indicated in table 4 , lower and upper respiratory symptoms as well as skin symptoms occurring upon exposure to specific triggers, such as animals, dust, trees, grass, flowers or food, were more frequently reported in Hamburg than in Erfurt $(\mathrm{p}<0.005$ each).

\section{Spirometry}

Mean spirometric findings and results of responsiveness testing are presented in table 5. Mean absolute FVC values in Hamburg were slightly higher than in Erfurt $(\mathrm{p}<0.05)$, but FEV1 as (\% predicted) was lower in Hamburg $(\mathrm{p}<0.0005)$. An FEV1 below the 5th percentile of the residuals of FEV1 in a gender-specific linear regression analysis of FEV1 versus age and height for the data sets of both cities was more frequently found in Hamburg than in Erfurt $(\mathrm{p}<0.005)$.

\section{Bronchial responsiveness}

The percentage of subjects hyperresponsive to methacholine was higher in Hamburg than in Erfurt, and the mean log slope of the dose-response curves for methacholine was higher in Hamburg than in Erfurt $(\mathrm{p}<0.05$ each).

In both centres, hyperresponsiveness was found significantly more frequently in females than in males $(\mathrm{p}<0.05$ each). After introducing absolute values of baseline FEV1 into a linear regression of the maximum fall of FEV1 after methacholine, the effect of gender was no longer statistically significant.

\section{Skin-testing}

Prevalences of positive skin tests in the two cities are presented in figure 1a. In Hamburg, higher rates of positive findings were observed for grass $(p<0.05)$, birch $(\mathrm{p}<0.0005)$, cat $(\mathrm{p}<0.0005)$, and D. pteronyssinus $(\mathrm{p}<0.05)$,

Table 5. - Lung function and airway responsiveness in Hamburg and Erfurt (mean values)

\begin{tabular}{|c|c|c|c|c|c|c|c|c|}
\hline & \multicolumn{3}{|c|}{ Hamburg } & \multicolumn{4}{|c|}{ Erfurt } & \multirow[b]{2}{*}{ p-value } \\
\hline & M & $\mathrm{F}$ & $\Sigma$ & M & $\mathrm{F}$ & $\Sigma$ & Adjusted $\#$ & \\
\hline \multicolumn{9}{|l|}{ Spirometry } \\
\hline FEV1/FVC \% & 81 & 83 & 82 & 82 & 83 & 83 & 83 & 0.0077 \\
\hline FEV1 $\%$ pred & 104 & 105 & 105 & 107 & 107 & 107 & 107 & 0.0001 \\
\hline Abnormal FEV1\% & 6.6 & 6.6 & 6.6 & 2.6 & 2.9 & 2.8 & 2.8 & 0.0006 \\
\hline \multicolumn{9}{|l|}{ Bronchial responsiveness } \\
\hline Hyperresponsiveness $^{\dagger} \%$ & 18 & 33 & 25 & 11 & 27 & 18 & 19 & 0.0059 \\
\hline $\log ($ dose-response slope +1$)$ & 0.085 & 0.197 & 0.138 & 0.059 & 0.120 & 0.088 & 0.089 & 0.0005 \\
\hline Slope $\geq 0.1$ & 14.9 & 32.1 & 23.0 & 8.6 & 25.8 & 16.7 & 17.0 & 0.0051 \\
\hline Bronchodilation tests & $0 / 1$ & $3 / 5$ & & - & $2 / 3$ & & & \\
\hline
\end{tabular}

\#: adjusted for age and gender distribution in Hamburg; +: defined by the 5th percentile of the residuals of FEV1 in a genderspecific linear regression analysis of FEV1 versus age and height for the data sets of Hamburg and Erfurt; ${ }^{\dagger}$ : percentage of subjects with a PD20 $<2.0 \mathrm{mg}$ or with a positive response to a bronchodilator test; $\$$ : number of positive bronchodilator tests $(\Delta \mathrm{FEV} 1$ $\geq 15 \%$ ). M: male; F: female; FEV1: forced expiratory volume in one second; FVC: forced vital capacity; \% pred: percentage of predicted value; PD20: provocative dose of methacholine causing a 20\% fall in FEV1; $\triangle$ FEV1: difference in FEV1. 
a)

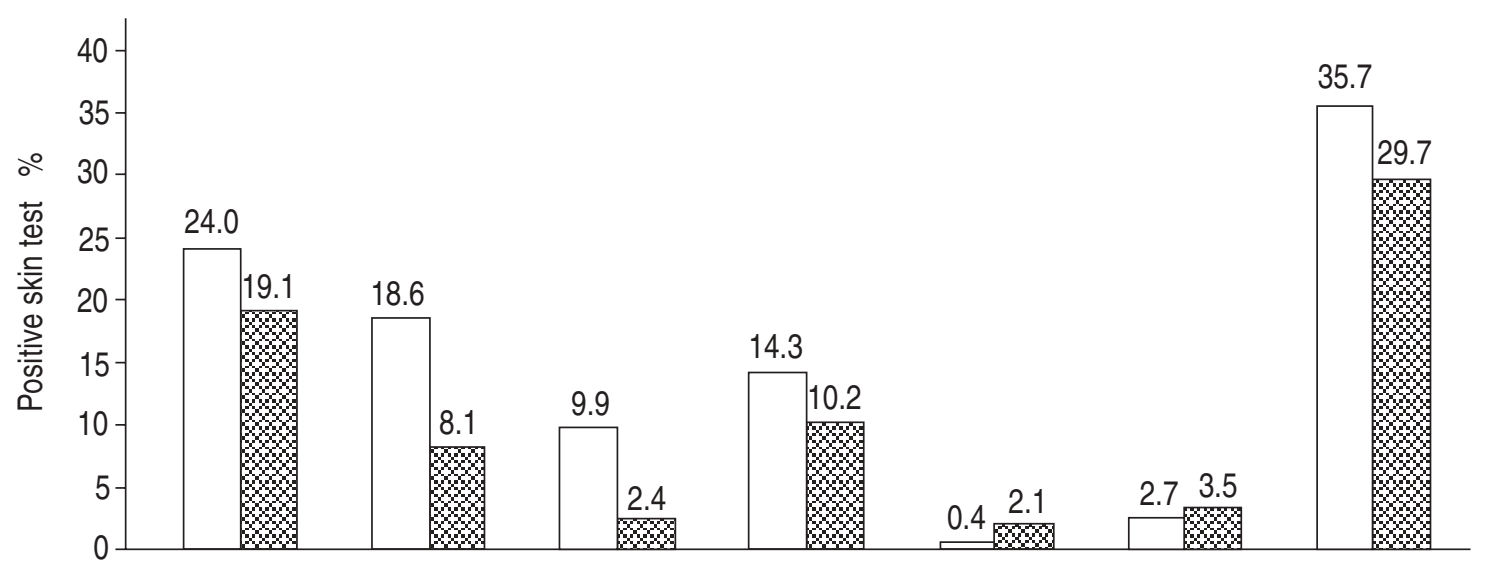

b)

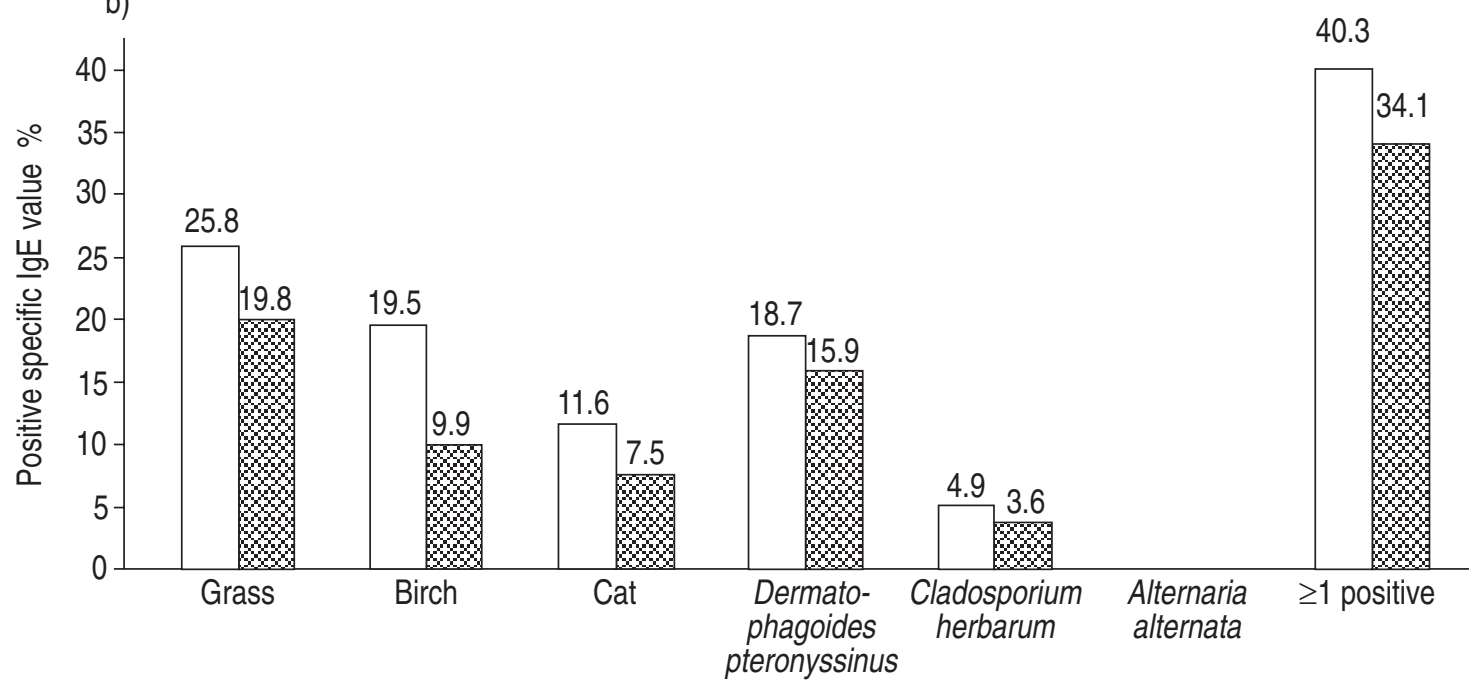

Fig. 1. - a) Prevalence of positive skin test reactions (wheal diameter $\geq 3 \mathrm{~mm}$ ); and b) of positive specific immunoglobulin $\mathrm{E}$ (IgE) values $\left(>0.35 \mathrm{kU} \cdot \mathrm{L}^{-1}\right.$; radioallergosorbent test (RAST)) in study participants from Hamburg ( $\square$ ) and Erfurt ( $\square$ ).

whereas sensitization against $C$. herbarum was more frequent in Erfurt $(\mathrm{p}<0.005)$, and no difference was observed for Alternaria alternata. At least one positive wheal was present in $36 \%$ of the subjects tested in Hamburg and $30 \%$ of those in Erfurt $(\mathrm{p}<0.05)$.

\section{Serum $\operatorname{Ig} E$}

Mean total serum IgE was significantly lower in Hamburg than in Erfurt (25.5 vs $41.6 \mathrm{kU} \cdot \mathrm{L}^{-1}$; $\left.\mathrm{p}<0.0005\right)$. Mean percentage of subjects with positive specific IgE values are given in figure 1b. In Hamburg, sensitization defined by a specific IgE level above $0.35 \mathrm{kU} \cdot \mathrm{L}^{-1}$ was more frequent than in Erfurt with respect to all allergens tested, the differences being significant for grass $(\mathrm{p}<0.05)$, birch $(\mathrm{p}<0.0005)$ and cat $(\mathrm{p}<0.05)$. No significant difference was observed for $D$. pteronyssinus and $C$. herbarum. In subjects with a positive response in the methacholine challenge, total $\mathrm{IgE}$ was higher than in subjects with a negative methacholine challenge (53.5 vs $22.9 \mathrm{kU} \cdot \mathrm{L}^{-1}$ in Hamburg and 46.5 vs $38.9 \mathrm{kU} \cdot \mathrm{L}^{-1}$ in Erfurt).

\section{Multiple logistic regression analysis}

Table 6 contains the results of nine regression models that test the influence of location, gender, and potential risk factors on the prevalence of positive skin tests and bronchial hyperresponsiveness. The respective figures on positive specific IgE values as outcome variables are not given separately, since in the respective models they essentially provided the same information as the skin test data. The study area of Hamburg and female gender were significantly associated with increased bronchial responsiveness in all the models. However, the study location was no longer a predictor of positive skin tests or positive specific IgE values when a positive family history of atopy (model IV) or a history of heating (model VII) or cooking (model VIII) by open coal, coke or wood fire or gas were taken into account. Current exposure to passive smoke but not smoke exposure during pregnancy and childhood was a significant predictor of bronchial hyperresponsiveness but not of atopic sensitization (model V). The same was true for current active smoking (model VI). These two variables, however, had no major influence on the odds 
Table 6. - Results of the logistic regression analyses with positive skin test reaction and bronchial responsiveness, respectively, as dependent variables

\begin{tabular}{|c|c|c|c|c|c|c|c|}
\hline \multirow{2}{*}{$\begin{array}{l}\text { Model } \\
\text { No. }\end{array}$} & \multirow[b]{2}{*}{ Factor entered in the model } & \multicolumn{3}{|c|}{ Positive skin-prick test ${ }^{\#}$} & \multicolumn{3}{|c|}{ Bronchial responsiveness ${ }^{\dagger}$} \\
\hline & & OR & $95 \% \mathrm{CI}$ & p-value & OR & $95 \% \mathrm{CI}$ & p-value \\
\hline \multirow[t]{2}{*}{ I } & Region: Hamburg & 1.29 & $(1.05-1.59)$ & 0.0154 & 1.46 & $(1.13-1.90)$ & 0.0039 \\
\hline & Gender: female & 0.80 & $(0.65-0.98)$ & 0.0315 & 2.47 & $(1.92-3.17)$ & $<0.0001$ \\
\hline \multirow[t]{5}{*}{ II } & Region: Hamburg & 1.25 & $(1.01-1.54)$ & 0.0365 & 1.45 & $(1.12-1.88)$ & 0.0053 \\
\hline & Gender: female & 0.82 & $(0.67-1.01)$ & 0.0561 & 2.49 & $(1.94-3.20)$ & $<0.0001$ \\
\hline & Siblings: one & 0.89 & $(0.67-1.18)$ & 0.4079 & 0.95 & $(0.67-1.34)$ & 0.7785 \\
\hline & two & 1.03 & $(0.74-1.41)$ & 0.8779 & 0.81 & $(0.54-1.21)$ & 0.3030 \\
\hline & more than two & 0.64 & $(0.46-0.89)$ & 0.0076 & 0.84 & $(0.56-1.24)$ & 0.3722 \\
\hline \multirow[t]{4}{*}{ III } & Region: Hamburg & 1.28 & $(1.04-1.58)$ & 0.0197 & 1.40 & $(1.08-1.82)$ & 0.0116 \\
\hline & Gender: female & 0.81 & $(0.66-1.00)$ & 0.0508 & 2.51 & $(1.95-3.24)$ & $<0.0001$ \\
\hline & Family history of asthma: parents & 1.02 & $(0.71-1.47)$ & 0.9194 & 1.15 & $(0.75-1.77)$ & 0.5191 \\
\hline & siblings & 1.26 & $(0.77-2.08)$ & 0.3613 & 2.67 & $(1.58-4.51)$ & 0.0002 \\
\hline \multirow[t]{4}{*}{ IV } & Region: Hamburg & 1.16 & $(0.93-1.43)$ & 0.1896 & 1.39 & $(1.06-1.81)$ & 0.0164 \\
\hline & Gender: female & 0.77 & $(0.62-0.95)$ & 0.0132 & 2.52 & $(1.95-3.26)$ & $<0.0001$ \\
\hline & Family history of atopy: parents & 1.71 & $(1.34-2.18)$ & $<0.0001$ & 1.16 & $(0.87-1.54)$ & 0.3260 \\
\hline & siblings & 1.63 & $(1.27-2.10)$ & 0.0001 & 1.23 & $(0.91-1.66)$ & 0.1714 \\
\hline \multirow[t]{5}{*}{ V } & Region: Hamburg & 1.26 & $(1.02-1.55)$ & 0.0311 & 1.37 & $(1.04-1.79)$ & 0.0226 \\
\hline & Gender: female & 0.80 & $(0.65-0.99)$ & 0.0368 & 2.74 & $(2.11-3.56)$ & $<0.0001$ \\
\hline & Smoke exposure: pregnancy or as child & 0.96 & $(0.77-1.20)$ & 0.7476 & 0.96 & $(0.73-1.27)$ & 0.7791 \\
\hline & Current & 1.20 & $(0.97-1.48)$ & 0.0898 & 1.37 & $(1.05-1.78)$ & 0.0187 \\
\hline & Positive skin test ${ }^{\#}$ & & & & 2.73 & $(2.11-3.53)$ & $<0.0001$ \\
\hline \multirow[t]{5}{*}{ VI } & Region: Hamburg & 1.30 & $(1.06-1.60)$ & 0.0120 & 1.40 & $(1.08-1.83)$ & 0.0126 \\
\hline & Gender: female & 0.79 & $(0.64-0.97)$ & 0.0246 & 2.79 & $(2.15-3.61)$ & $<0.0001$ \\
\hline & Active smoking: current & 0.92 & $(0.73-1.15)$ & 0.4520 & 1.44 & $(1.08-1.92)$ & 0.0136 \\
\hline & & 0.73 & $(0.55-0.97)$ & 0.0278 & 1.21 & $(0.86-1.72)$ & 0.2743 \\
\hline & Positive skin test ${ }^{\#}$ & & & & 2.68 & $(2.07-3.46)$ & $<0.0001$ \\
\hline \multirow[t]{4}{*}{ VII } & Region: Hamburg & 1.24 & $(0.99-1.55)$ & 0.0568 & 1.58 & $(1.20-2.09)$ & 0.0013 \\
\hline & Gender: female & 0.80 & $(0.65-0.98)$ & 0.0295 & 2.51 & $(1.95-3.23)$ & $<0.0001$ \\
\hline & Heating by open coal, wood or wood fire & 0.88 & $(0.66-1.16)$ & 0.3532 & 1.25 & $(0.89-1.76)$ & 0.2021 \\
\hline & Heating by open gas fire & 0.99 & $(0.60-1.66)$ & 0.9835 & 1.65 & $(0.92-2.95)$ & 0.0928 \\
\hline \multirow[t]{4}{*}{ VIII } & Region: Hamburg & 1.19 & $(0.95-1.49)$ & 0.1400 & 1.57 & $(1.18-2.08)$ & 0.0021 \\
\hline & Gender: female & 0.80 & $(0.65-0.98)$ & 0.0299 & 2.48 & $(1.93-3.19)$ & $<0.0001$ \\
\hline & Cooking by open coal, wood or wood fuel & 1.94 & $(0.55-6.78)$ & 0.2997 & 4.21 & $(1.05-16.89)$ & 0.0427 \\
\hline & Cooking by gas & 0.78 & $(0.61-1.01)$ & 0.0621 & 1.12 & $(0.82-1.53)$ & 0.4627 \\
\hline \multirow[t]{3}{*}{ IX } & Region: Hamburg & 1.27 & $(1.03-1.56)$ & 0.0226 & 1.45 & $(1.12-1.88)$ & 0.0049 \\
\hline & Gender: female & 0.80 & $(0.65-0.98)$ & 0.0287 & 2.47 & $(1.92-3.17)$ & $<0.0001$ \\
\hline & Sleep with windows always open in winter & 0.76 & $(0.62-0.94)$ & 0.0096 & 0.87 & $(0.68-1.12)$ & 0.2832 \\
\hline
\end{tabular}

\#: at least one wheal diameter from the six allergens tested $\geq 3 \mathrm{~mm}$; ${ }^{\dagger}$ PD20 $\leq 2.0 \mathrm{mg}$ or positive response to a bronchodilator test. OR: odds ratio; 95\% CI: 95\% confidence interval; PD20: provocative dose of methacholine causing a $20 \%$ fall in forced expiratory volume in one second. P-values result from testing the hypothesis that $\mathrm{OR}=1$.

ratios of the three dependent variables between the two study locations. If all variables given in table 6 were entered into the model simultaneously, female gender, being an ex-smoker and sleeping with the windows open in winter were associated with a lower risk of a positive skin test, whereas a family history of atopy was associated with a higher risk. Bronchial hyperresponsiveness was positively associated with female gender, having siblings with asthma, and a positive skin test, whereas in this combined model, living in Hamburg was only marginally significant as a risk factor.

\section{Discussion}

In this study, we compared different measures of respiratory health and atopic status between two cities in
West and East Germany. For more than four decades, there had been major differences in housing and living conditions and environmental pollutants between the two cities $[10,11]$. We found a higher prevalence of most respiratory symptoms, lung function impairment, bronchial hyperresponsiveness, and atopic sensitization against a variety of allergens in the Western than in the Eastern city. The latter was consistently true both for the skin test results and specific IgE values against indoor allergens, such as cat and house dust mite, as well as outdoor allergens, such as grass and birch. In addition, symptoms upon exposure to animals, dust, trees, grass, or flowers were more frequently reported in Hamburg than in Erfurt.

Therefore, our findings in adults resemble what has been observed in children. VON Mutius et al. [12], 
studying a total of 7,653 children 9-11 years of age, found a higher prevalence of doctor-diagnosed asthma and hay fever among those living in cities in West Germany as compared to East Germany. In addition, a higher prevalence of bronchial hyperresponsiveness as assessed by cold air challenge was found in West than in East Germany. Atopic sensitization to grass and birch pollen, cat, mite, and hazel pollen was more frequently found in West than in East Germany. In a study on 2,054 preschool children, BEHRENDT et al. [13] reported slightly, but not significantly, higher prevalences of doctor-diagnosed allergy and hay fever in West than in East Germany. The prevalence of positive radio allergosorbent test (RAST) results against birch were higher in the Western than in the Eastern areas, but this was not true for grass or house dust [13]. In this study, however, the difference in total IgE, with higher mean values in East than in West Germany, was even more pronounced than the difference observed in the present study subjects. The higher prevalence of allergic sensitization in West Germany is further supported by the data on IgE antibodies against indoor allergens, such as house dust mite and cat, which have been obtained in 901 vocational pupils from West and East Germany. No such differences were found in sensitization against outdoor allergens, such as rye, timothy grass, birch and mugwort [14]. BRABÄCK et al. [15], in a comparison of atopic sensitization and respiratory symptoms among Swedish and Polish school children, reported that children living in urban Sweden, as compared to urban Poland, were more frequently diagnosed as being asthmatic by a doctor, and had higher prevalences of positive skin-prick test reactions against mugwort, timothy, birch and cat.

Several studies have indicated a rising trend in atopic diseases and asthma over time both in children [16-21] and adolescents [2, 22, 23]. Most authors suggest that this is not simply due to improved diagnostic trends. The reasons are only partly known [24, 25], but among those being discussed are number of siblings [26], dietary factors [27], exposure to outdoor allergens [28], ozone [29], nitrogen dioxide [30] and sulphur dioxide [31], and the combination of the latter [32], as well as indoor exposure to environmental tobacco smoke [33] and mites [34].

It may, therefore, be speculated that similar factors are responsible for the geographical differences and the rising trend over time, both factors sometimes being illustrated as "Westernization". Regarding the time trend, there is only limited scientific evidence for an increasingly "toxic" or "allergenic" environment [35], thus leaving the reasons responsible for the observed time trends mostly unknown.

In our study, a positive family history of atopy among parents and siblings was a strong risk factor for a positive skin-prick test. If it was taken into account, the difference in sensitization rates between the two cities was no longer significant (table 6 , model IV). This is not surprising, given the well-known hereditary component in atopy. However, this association adds little to the interpretation of "external" risk factors.

The differences described in our cross-sectional study in Hamburg and Erfurt should be discussed in view of potential risk factors in the two cities. The average number of siblings in East Germany was higher than in West Germany, thus supporting the observation of vON Mutius et al. [26], who described a decreasing trend of atopic sensitization with an increasing number of siblings. Although subjects from Eastern Germany had more frequently attended a playschool or nursery, no significant differences were reported regarding serious respiratory tract infections which may predispose to impaired lung function [36], but not necessarily to atopy [37]. Since adjusting for the number of siblings did not significantly alter the odds ratio of positive skin tests, specific IgE values or bronchial hyperresponsiveness between the two cities, this does not seem to be a relevant confounder for the observed difference.

Both previous and current exposure to environmental tobacco smoke exposure were more frequently reported in Hamburg than in Erfurt. Current passive smokers had a higher degree of bronchial responsiveness when adjusting for region, sex and positive skin test. Although environmental tobacco smoke exposure during childhood [38] and adulthood [39] may predispose to asthma, the comparatively small difference in self-reported environmental tobacco smoke exposure makes a major contribution to the considerable difference in asthma prevalence unlikely.

Housing conditions differed strikingly between West and East Germany, e.g. heating by open coal, coke or wood fire as well as cooking by gas were four- to sixfold more frequently reported in the East than in the West. This may have led to higher indoor concentrations of sulphur dioxide, particulate matter and nitrogen dioxide, which have been linked to an impairment of respiratory health, especially in children [30, 31]. However, no indoor measurements of these pollutants are available, and it is unknown whether there were systematic differences between cities in reporting potential risk factors. Interestingly, cooking by open coal, coke or wood fuel was related to higher levels of bronchial responsiveness, and was a better predictor of a positive skin test than was living in Hamburg. In the respective statistical model, the odds ratio in sensitization rates between the two cities was no longer significant.

Fitted carpets, which were more frequently used in Hamburg than in Erfurt, especially in bedrooms, may predispose to growth of mites, as VAN STRIEN et al. [40] found 6-14 times higher D. pteronyssinus antigen I (Der $p \mathrm{I})$ concentrations in dust from carpeted floors than in dust from floors with a smooth floor covering. Furthermore, in the present study, mould or mildew was reported two- to threefold more frequently in Hamburg than in Erfurt. In the study by DeKKer et al. [41], living in a damp home and exposure to environmental tobacco smoke were significantly associated with increased reports of physician-diagnosed asthma in children, and BRUNEKREEF [42] reported a positive association of damp stains or mould growth with asthma in male adults. It is noteworthy that higher $\operatorname{Der} p$ I concentrations were observed in homes with reported or observed signs of dampness [40]. Thus, the higher rates of sensitization against $D$. pteronyssinus in Hamburg may, in part, reflect a climate more comfortable for mites under "Western" housing conditions.

The higher cutaneous sensitization rates against cat 
allergen, which were observed in Hamburg, cannot be easily explained as a consequence of cats being more frequently kept in the house, since specific $\operatorname{IgE}$ values against cat allergen did not differ significantly between the two cities. However, in addition to the current or previous presence of a cat in the home, high indoor humidity and the presence of wall-to-wall carpets have been shown to increase the risk for high exposure to cat allergen [43].

Likewise, the higher prevalence of positive skin tests and specific IgE values against birch might reflect a higher exposure to birch allergen in Hamburg than in Erfurt. No comparable data on pollen counts are available, however.

Parasitic infection may be a factor contributing to the observed difference in atopy between the two cities. Parasites may trigger IgE production [44], and there may be an inverse correlation between parasitic $\operatorname{IgE}$ and atopic disease [45]. In immigrants to Sweden with decreasing parasite contact, IgE levels lowered, but prevalence of sensitization against birch pollen increased [45]. In the study by BEHRENDT et al. [13], up to $30 \%$ of East German children versus only $5 \%$ of West German children reported ever having had a parasitic infection. It has been speculated that stimulation of naive resting helper T-cells by worm-like antigens may stimulate type 2 T-helper (Th2) responses, leading to elimination of worms but enhancing viral immunopathology, whereas virus-like antigens stimulate type 1 T-helper (Th1) responses, thus, leading to antiviral immunity but at the cost of allowing worms to persist [46]. However, no data on the frequency of helminthic infestation are available in West and East Germany to clarify the role of worms in the prevalence of atopy within this setting.

Although we observed no major gender differences with respect to most symptoms or to parameters of atopic sensitization in either centre, bronchial hyperresponsiveness was found significantly more frequently in females than in males. Taking the absolute values of baseline FEV1 into account, the gender difference disappeared. This phenomenon has been described previously by others [47], supporting the view that the smaller the airway calibre, the greater the likelihood of bronchial hyperresponsiveness. From this observation, it may be suggested that the definition of bronchial hyperresponsiveness should take baseline airway calibre into account. Since there was no statistically significant difference in absolute FEV1 values between Hamburg and Erfurt, the geographical difference in bronchial hyperresponsiveness is unlikely to be biased by geometrical factors of the airways.

In an epidemiological study like ours, several aspects of possible bias and confounding have to be addressed. Both in Stage I and Stage II, age and gender distribution did not differ from those of the target population. In addition, we tried to assess the possible Stage I bias due to nonresponding by comparing the prevalence of symptoms between subjects responding quickly and those responding after reminders. There was a decrease in symptom rates between Stage I and II for several symptoms, e.g. wheeze and hay fever, as has been described in other centres of the EC Respiratory Health Survey [48]. This effect did not differ significantly between Hamburg and Erfurt (data not shown). On the other hand, the percentage of subjects not responding was similar in both centres. Therefore, a major bias due to nonresponding in Stage I is unlikely. Although infomation on respiratory symptoms was missing in 20-30\% of the eligible population sample, there were no significant differences in age and sex distribution between eligible subjects and Stage I responders.

A potential Stage II bias was addressed in several ways. Firstly, among the participants in Stage II tests, we found that the percentages of positive answers asked in Stage I and Stage II were not significantly different in either city. Secondly, we compared the consistency of the relationship between symptoms and objective measurements between both study centres. The percentage of subjects answering the questions related to asthma in the affirmative among those with bronchial hyperresponsiveness was considerably higher in Hamburg than in Erfurt, and the same was true for the percentage of subjects reporting allergic rhinitis among those with any positive skin test. Therefore, although it is unlikely that symptomatic subjects tended to be more willing to participate in the Stage II tests, diagnostic labelling of symptoms appeared to differ between centres (data not shown) which prevented us from defining the "true" prevalence of, e.g. asthma, beyond the information collected in the questionnaires. However, this does not critically affect the interpretation of our figures on atopic sensitization, as these depend on highly standardized methods not prone to bias by differential interpretation. In view of the uncertainties of the relationship between symptoms and functional impairment, we preferred not to perform any extrapolation from data collected in Stage II to those obtainable in Stage I.

The recruitment of subjects, the questionnaires and the instruments for determining bronchial responsiveness and atopy, as well as the procedures for quality control, followed the protocol of the EC Respiratory Health Survey [1]. The questionnaires had been validated in several previous investigations [2-6], and the instruments for measurements had been standardized and validated within the multinational survey. Skintesting was performed with Phazets, whenever they were allowed to be used in Germany, since the precision of that method is superior to other puncture tests [49]. Due to the strict quality control, comparability of the present results with those obtained in other centres of the survey is ensured. However, one has to be careful in drawing conclusions from the comparison of only two centres, since the populations studied may differ in several aspects not recognized in this survey, and the reliability of an exposure-response gradient depending only on two points is limited. Although the only methods available for demonstrating causation between environmental factors on the one hand and atopy and asthma on the other are randomized, controlled interventions or longitudinal studies carefully monitoring all suspected factors, we feel that this type of cross-sectional study can provide some evidence for risk factors on which we need to focus our attention.

One observation from the present study is that longterm exposure to high concentrations of sulphur dioxide and particulate matter appears not to primarily facilitate the development of asthma, airway hyperresponsiveness and atopy. Childhood factors and exposure to indoor 
allergens and irritants may be more likely to be responsible for the differences observed between the two cities. However, it has to be kept in mind that the study was not designed to examine indoor influences in-depth. To investigate the causal role of risk factors of indoor environment or East/West lifestyle, further investigations are necessary.

Acknowledgements: The authors acknowledge the excellent technical support of C. Ramin, G. Schmudde, U. Willenbrock (Hamburg), S. Pirstat (Erfurt) and A. Schneider (Munich) and valuable comments on the manuscript by E. von Mutius (Munich).

\section{References}

1. Burney PGJ, Luczynska C, Chinn S, Jarvis D, for the European Community Respiratory Health Survey. The European Community Respiratory Health Survey. Eur Respir J 1994; 7: 954-960.

2. Burney PGJ, Chinn S. Developing a new questionnaire for measuring the prevalence and distribution of asthma. Chest 1987, 91: 79s-83s.

3. Burney PGJ, Chinn S, Britton JR, Tattersfield AE, Papacosta AO. What symptoms predict the bronchial response to histamine? Evaluation in a community survey of the Bronchial Symptoms Questionnaire (1984) of the IUATLD. Int J Epidemiol 1989; 18: 165-173.

4. Abramson MJ, Hensley MJ, Saunders MA, Wlodarczyk $\mathrm{JH}$. Evaluation of a new asthma questionnaire. J Asthma 1991; 28: 129-139.

5. American Thoracic Society. Epidemiology Standardization Project, executive committee. Recommended respiratory disease questionnaires for use with adults and children in epidemiological research. Am Rev Respir Dis 1978; 118: 7-52.

6. Office of Populations Censuses and Surveys. Classification of occupations. London, Her Majesty's Stationery Office, 1970.

7. Quanjer PhH, Tammeling GH, Cotes JE, Pedersen OF, Peslin R, Yernault J-C. Lung volumes and forced ventilatory flows. Eur Respir J 1993; 6 (suppl. 16): 5-40.

8. Chinn, S, Burney PG, Britton JR, Tattersfield AE, Higgins BG. Comparison of PD20 with two alternative measures of response to histamine challenge in epidemiological studies. Eur Respir J 1993; 6: 670-679.

9. Belin L, Dreborg S, Einarsson R, et al. Phazet, a new type of skin-prick test: calibration and stability. Allergy 1985; 40 (Suppl. 4): 60-63.

10. Magnussen H, Jörres R, Nowak D. Effect of air pollution on the prevalence of asthma and allergy: lessons from the German reunification. Thorax 1993; 48: 879-881.

11. Wichmann H-E, Heinrich J. Health effects of high level exposure to traditional pollutants in East Germany: review and ongoing research. Environ Health Perspect 1995; 103 (Suppl. 2): 29-35.

12. Mutius E von, Martinez FD, Fritzsch C, Nicolai T, Röll G, Thiemann H-H. Prevalence of asthma and atopy in two areas of West and East Germany. Am J Respir Crit Care Med 1994; 149: 358-364.

13. Behrendt H, Krämer U, Dolgner R, et al. Elevated levels of total serum IgE in East German children: atopy, parasites or pollutants? Allergol J 1993; 2: 31-40.

14. Klein K, Dathe R, Goellnitz S, Jäger L. Allergies: a comparison between two vocational schools in East and West Germany. Allergy 1992; 47 (suppl. 12): 259.
15. Brabäck L, Breborowicz A, Dreborg S, Knutsson A, Pieklik H, Björkstén B. Atopic sensitisation and respiratory symptoms among Polish and Swedish school children. Clin Exp Allergy 1994; 24: 826-835.

16. Varonier HS, de Haller J, Schopfer C. Prévalence de l'allergie chez les enfants et les adolescents. Helv Paediatr Acta 1984; 39: 129-136.

17. Burr M, Butland B, King S, Vaughan-Williams E. Changes in asthma prevalence: two surveys fifteen years apart. Arch Dis Child 1989; 64: 1452-1456.

18. Burney, PJ, Chinn S, Rona RJ. Has the prevalence of asthma increased in children? Evidence from the national study on health and growth 1973-1986. BMJ 1990; 300: 1306-1310.

19. Robertson CF, Heycock E, Bishop J, Nolan T, Olinsky A, Phelan PD. Prevalence of asthma in Melbourne schoolchildren: changes over 26 years. BMJ 1991; 302: 1116-1118.

20. Ninan T, Russel G. Respiratory symptoms and atopy in Aberdeen schoolchildren: evidence from two surveys 25 years apart. BMJ 1992; 304: 873-875.

21. Rusznak C, Devalia JL, Davies RJ. The impact of pollution on allergic disease. Allergy 1994; 49: 21-27.

22. Aberg N. Asthma and allergic rhinitis in Swedish conscripts. Clin Exp Allergy 1989; 19: 59-63.

23. Shaw, RA, Crane J, O'Donnell TV, Portous LE, Coleman ED. Increasing asthma prevalence in a rural New Zealand adolescent population: 1975-1989. Arch Dis Child 1990; 65: 1319-1323.

24. Peat JK. The rising trend in allergic illness: which environmental factors are important? Clin Exp Allergy 1994; 24: 797-800.

25. Newman-Taylor A. Environmental determinants of asthma. Lancet 1995; 345: 296-299.

26. Mutius E von, Martinez FD, Fritzsch C, Nicolai T, Reitmeir P, Thiemann H-H. Skin test reactivity and number of siblings. BMJ 1994; 308: 692-695.

27. Gregg I. Epidemiological research into asthma: the need for a broad perspective. Clin Exp Allergy 1986; 16: 17-23.

28. Ishizaki T, Koizumi K, Ikemori R, Ishiyama Y, Kushibiki E. Studies of prevalence of Japanese cedar pollinosis among the residents in a densely cultivated area. Ann Allergy 1987; 58: 265-270.

29. Jörres R, Nowak D, Magnussen H. The effect of ozone exposure on allergen responsiveness in subjects with asthma or rhinitis. Am J Respir Crit Care Med 1996; 153: 56-64.

30. Braun-Fahrländer C, Ackermann-Liebrich U, Schwartz J, Gnehm HP, Rutishauser M, Wanner HU. Air pollution and respiratory symptoms in preschool children. Am Rev Respir Dis 1992; 145: 42-47.

31. Roemer W, Hoek G, Brunekreef B. Effect of ambient winter air pollution on respiratory health of children with chronic respiratory symptoms. Am Rev Respir Dis 1993; 147: 118-124.

32. Devalia JL, Rusznak C, Herdman MJ, Trigg CJ, Tarraf $\mathrm{H}$, Davies RJ. Effect of nitrogen dioxide and sulphur dioxide on airway response of mild asthmatic patients to allergen inhalation. Lancet 1994; 344: 1668-1671.

33. Young S, Le Souef PN, Geelhoed GC, Stick SM, Turner KJ, Landau LI. The influence of a family history of asthma and parental smoking on airway responsiveness in early infancy. $N$ Engl J Med 1991; 324: 1168-1173.

34. Sporik R, Holgate ST, Platts-Mills TAE, Cogswell JJ. Exposure to house-dust mite allergen (Der $p$ I) and the development of asthma in childhood: a prospective study. N Engl J Med 1990; 323: 502-507. 
35. Seaton A, Godden DJ, Brown K. Increase in asthma: a more toxic environment or a more susceptible population? Thorax 1994; 49: 171-174.

36. Henderson FW, Stewart PW, Burchinal MR, et al. Respiratory allergy and the relationship between early childhood lower respiratory illness and subsequent lung function. Am Rev Respir Dis 1992; 145: 283-290.

37. Pullan CR, Hey EN. Wheezing, asthma, and pulmonary dysfunction 10 years after infection with respiratory syncytial virus in infancy. Br Med J 1982; 284: 1665-1669.

38. Martinez FD, Cline M, Burrows B. Increased incidence of asthma in children of smoking mothers. Pediatrics 1992; 89: 21-26.

39. Leuenberger P, Schwartz J, Ackermann-Liebrich U, et al. Passive smoking exposure in adults and chronic respiratory symptoms (Sapaldia Study). Am J Respir Crit Care Med 1994; 150: 1222-1228.

40. van Strien RT, Verhoeff AP, Brunekreef B, van Wijnen JH. Mite antigen in house dust: relationship with different housing characteristics in The Netherlands. Clin Exp Allergy 1994; 24: 843-853.

41. Dekker C, Dales R, Bartlett S, Brunekreef B, Zwanenburg $\mathrm{H}$. Childhood asthma and the indoor environment. Chest 1991; 100: 922-926.

42. Brunekreef B. Damp housing and adult respiratory symptoms. Allergy 1992; 47: 498-502.
43. Munir AKM, Björkstén B, Einarsson R, et al. Cat ( Fel $d \mathrm{I}), \operatorname{dog}(\operatorname{Can} f \mathrm{I})$, and cockroach allergens in homes of asthmatic children from three climatic zones in Sweden. Allergy 1994; 49: 508-516.

44. King CL, Low CC, Nutman TB. IgE production in human helminth infection: reciprocal interrelationship between IL-4 and IFN- $\gamma$. J Immunol 1993; 150: 18731880.

45. Kalyoncu AF, Stalenheim G. Serum IgE levels and allergic spectra in immigrants to Sweden. Allergy 1992; 47: 277-280.

46. Openshaw PJM, O'Donnell DR. Asthma and the common cold: can viruses imitate worms? Thorax 1994; 49: 101-103.

47. Kanner RE, Connett JE, Altose MD, et al., for the Lung Health Study Research group. Gender difference in airway hyperresponsiveness in smokers with mild COPD: the Lung Health Study. Am J Respir Crit Care Med 1994; 150: 956-961.

48. deMarco R, Verlato G, Zanolin E, Bugiani M, Drane JW. Nonresponse bias in EC Respiratory Health Survey in Italy. Eur Respir J 1994; 7: 2139-2145.

49. Demoly P, Bousquet J, Manderscheid J-C, Dreborg S, Dhivert H, Michel F-B. Precision of skin prick and puncture tests with nine methods. J Allergy Clin Immunol 1991; 88: 758-762. 